\title{
Digital Platform Workers under COVID-19: A Subaltern Perspective
}

\author{
Silvia Masiero \\ Department of Informatics \\ University of Oslo \\ Ole-Johan Dahls Hus, Gaustadalleèn 23B \\ N-0373 Norway \\ silvima@ifi.uio.no
}

\begin{abstract}
Digital labour is widely depicted as a carrier of economic opportunities for poor and marginalised individuals. Such an orthodoxy is however questioned from research pointing at the structural vulnerabilities of digital work, vulnerabilities that the COVID-19 crisis has highlighted on a global scale. The central contribution of this paper is that subalternity theory offers the intellectual tools to understand the structural vulnerability of digital platform workers, setting the ground for studying emerging forms of collective resistance among them. Drawing on a data repository of web sources collected through the first four months of the COVID-19 crisis, it reveals the establishment of a mainstream discourse from platform representatives, the presence of forms of systematic devoicing among workers, and the emergence of a paternalistic attitude enacted by the platforms in continuity with the pre-crisis situation. Implications are drawn for the literature on digital labour, and for the study of emerging solidarity networks among workers subjected to subalternity.
\end{abstract}

\section{Introduction}

The diffusion of digital labour, worldwide and especially across the Global South, is underpinned by an orthodoxy depicting digital work as a carrier of opportunities for marginalised individuals. Such a view assumes that digital platforms present opportunities on physical (e.g. food delivery, ride-hailing apps) and digital tasks (on platforms such as UpWork, Freelancer or Amazon Mechanical Turk), which offer flexibility to the worker and bypass the geographical and political barriers imposed by labour markets. Such an orthodoxy is subject to critique, especially highlighting the nature of digital labour as precarious and vulnerable $[4,16]$ and a structural lack of accountability of digital platforms to their workers $[18,44]$. In this light, a recent literature has highlighted forms of resistance enacted by digital workers across the globe, ranging from organised protest $[18,10,4]$ to intra-familial and societal worker solidarity networks [33].

Against this backdrop, the current COVID-19 crisis has highlighted the severity of the vulnerabilities to which digital platform workers are exposed. Just a few weeks into the emergency, reports of mistreating and exploitation in the gig economy started emerging, detailing instances of lacking workers' protection and crucially, the refusal of digital labour platforms to account for their workers' conditions. Food delivery workers [23]; ride-hailing app drivers [4], as well as domestic workers finding their jobs through digital apps [40] are tied together by the common denominator of exposure to limited accountability of the platforms responsible for workers' protection and fair labour conditions under the pandemic. In April 2020, the Fairwork Foundation published a survey of 120 platforms across 23 countries, updated in September 2020 to include 191 platforms in 43 countries, highlighting the pervasiveness of such issues, as well as the asymmetries between conditions dictated to workers and promises for crisis interventions made by platform representatives on public media spaces [14].

In the light of COVID-19, emerging forms of resistance are unfolding among digital platform workers affected by the crisis. Data presented in this paper draw from a repository of blog posts, news items and company reports collected in the aftermath of the COVID-19 outbreak, relating to impacts suffered by gig workers and measures taken to mitigate these. The central contribution of this paper is that subalternity theory, in its seminal formulation by Guha \& Spivak [21], offers the intellectual tools to study the structural vulnerabilities of digital platform workers, as well as the mainstream discourse of protection constructed by platform owners in the light of the crisis. The COVID19 scenario, in which the economic vulnerability of 
workers makes existing forms of oppression more acute and severe, offers the conditions to study emerging forms of digital resistance, establishing dialogue between subalternity theory and the study of solidarity networks in the datafied society [6].

This paper is structured as follows. First, digital labour platforms and the discontents of precarity and vulnerability are introduced, illuminating heightening effects of COVID-19 on both aspects. Subalternity theory - with its concepts of mainstream discourse, devoicing and paternalism - is then introduced as a conceptual lens to study the vulnerabilities of platform workers in the COVID-19 situation. Analysis of a data repository of 68 web sources is then articulated according to such concepts. The study draws implications for the literature on digital labour, setting the ground for studying the emergence of solidarity networks among platform workers affected by the crisis.

\section{Digital Labour Platforms and COVID- 19}

Existing estimates of the size of the digital gig economy point to 60 million workers registered with online labour platforms, out of which 6 million currently active [26]. A substantial share of these workers is located in the Global South: citing Codagnone [11], Heeks [26] notes there is an estimated 45 million registered workers on Western-based online labour platforms, and uses surveys by Agrawal [2] and Lehdonvirta [31] to estimate 36 million of these being from the Global South with a prevalence in India, the Philippines, Pakistan and Bangladesh. Digital work is rapidly diffusing across African [3] and Latin American countries [20]. A recent projection says that in China, up to 400 million people (half the labour force) could be gig workers by $2036 .{ }^{1}$

Consisting of a geographically dispersed workforce, the gig economy is understood through different taxonomies of the sub-sectors that constitute it. Heeks [26] divides it into digital (online labour) and physical gig economy (location-based service delivery), where online labour refers to intangible work delivered online and location-based services (such as ride-hailing or food delivery) are organised digitally, but delivered physically. Graham and Woodcock [18] further divide online labour into microtask platforms (such as Amazon Mechanical Turk) involving short crowdsourced tasks, and freelance work platforms (such as Upwork or Freelancer) involving more specific skills and relations with clients. In a similar fashion, the Fairwork

\footnotetext{
${ }^{1} \mathrm{https}$ ://jamestown.org/program/under-a-covid-19-cloud-chinas-gigeconomy-comes-of-age/, accessed 20 October 2020
}

Foundation uses the terms gig work and crowdwork for the physical-digital dichotomy in point. ${ }^{2}$

As research in Information and Communication Technology for Development (ICT4D) increasingly turns to digital platforms as a research object $[22,35$, 39] discourse emerged on understanding theoretical links between digital labour platforms and socioeconomic development [33]. Surveys conducted across digital workers in the Global South reveal that these platforms have enabled workers to build earnings and skills [7], and that "positives outweigh negatives" for workers who find previously non-existing employment opportunities in digital work [12, 29, cited in 26]. Such positives originated a sustained orthodoxy of digital labour for development, leveraged in reports such as World Bank [45] and the Rockefeller Foundation [41] to portray digital work as a force for empowering marginalised people through sustained earnings.

Counteracting such theories is, however, criticism on the extent to which such an orthodoxy is a fair depiction of the effects of digital platforms on workers. A three-pronged taxonomy of critical objections is offered by Graham and Woodcock [18]: a first point pertains to new practices of digital work, such as tagging or moderating commercial content, which can involve looking at traumatic content for extended periods of time [18]. Other forms of emotional strain are suffered by workers, such as ride-hailing app drivers, exposed to disrespectful behaviour by users [15] and what is worse, to rating systems that empower users at the workers' expense [26]. Subjection to unfair bad ratings, which can result in deactivation and cannot normally be easily challenged [15], crystallises workers' disempowerment, adding to the risks intrinsic in their daily jobs [36].

A second issue results from the way digital labour platforms transform existing practices [18]. Commodified labour [27] results into increased casualisation generated, in turn, by outsourcing previously established work practices. Consequential to the transition to platforms is, in particular, the reclassification of workers from employees to freelancers - a move that, under multiple national legal frameworks [16], deprives the worker of employee protection systems that would otherwise be mandated. Issues resulting from such a transition notably include absence of holiday pay, health insurance or sick leave, retirement benefits, injury compensation and in some cases, even the guarantee of a minimum wage [8].

Thirdly, the geographical dispersion of workers combined with the non-cooperative nature of many tasks in digital work - often induces platform workers to compete rather than collaborate [18]. Competing for

\footnotetext{
${ }^{2}$ https://fair.work/principles/, accessed 20 October 2020
} 
the same jobs, facing risk of deactivation in case of low ratings or failure to complete a sufficient number of tasks, hampers the construction of solidarity networks among digital workers, increasing the difficulty of establishing formal and informal means to unionisation [33]. Information asymmetries [26] between workers and platform owners contribute to the difficulty of building such networks, with workers' classification as "freelancers" acting as a pretext for platforms to decline responsibilities [16]. As a result, in case of complaints, workers may find it hard to even be sure of "whom to complain to" in the first place [18].

This synopsis of problems reveals how, in response to an orthodoxy that views digital work as a form of empowerment of the marginalised through sustained earnings, a double structural problem emerges. A first component lies in the power asymmetries affecting workers, resulting in precarity [3] manifested through disempowering classifications (as "freelancers" rather than "employees") and rating systems that empower the customer to decide on workers' destiny, by ratings whose fairness is normally not overseen. A second component stems from informational asymmetry, resulting in workers not being aware of key mechanisms for seeking protection and grievance redressal. This contributes to workers' vulnerability, as informational gaps prevent any form of bargaining or worker negotiation from happening in equal terms [3].

Against this backdrop, with the global crisis initiated by the COVID-19 outbreak, such aspects of precarity and vulnerability have acquired new visibility, proliferating across narratives from digital workers worldwide. In the recent aftermath of the declaration of the COVID-19 outbreak as a pandemic by the World Health Organisation in March 2020, ethnographic accounts from gig workers revealed their frontline role in the pandemic, taking care of a plethora of services from food delivery to private transport - that national governments encourage people to use to enforce social distancing [4, 20, 23]. Platform workers are key workers under all aspects: as the Fairwork Foundation report [14] observes, their work substitutes key services, however exposing workers to the risk of contracting the COVID-19 infection by daily work practices. This conundrum, placing gig workers in a key position and yet a condition of perpetuated risk, illustrates the criticality of the workers' situation.

Such risk can be framed in terms of the issues of precarity and vulnerability illustrated above. In terms of precarity, numerous reports illustrate the difficulty of the economic condition in which workers are induced. With the widespread suspension of services from platforms deemed as "non-essential", many workers such as domestic cleaners [40] or workers of the beauty industry [46] have found themselves without secure incomes, whereas active workers in lockdown situations have lost an average of two-thirds of their income [14]. Vulnerability emerges in the same picture: ethnographic accounts reveal the physical proximity to which food delivery workers are forced in queues for collection [23], and the need of ride-hailing workers to keep working during the outbreaks to offset fixed costs of their work [20]. Such ethnographies concur with surveys [25] in stating the lack of accountability of platforms for the provision of essential protection, such as masks or hand sanitisers, which workers often have to supply by themselves, with few exceptions reported [14].

Drawn together, these accounts narrate the enhancement of fragility in conditions endured by digital platform workers during COVID-19. It has been argued [25] that the crisis has illuminated aspects of fragility that were already present, such as the conditions of structural precarity and vulnerability illustrated above. While the crisis results in greater visibility of such problems, few attempts have been made to theoretically conceptualise the roots of such issues for digital workers in light of the crisis. In this scenario, subalternity theory offers important concepts for theorisation.

\section{Digital Labour: A Subalternity Theory Lens}

In recent studies of ICT4D, subaltern visions have introduced critical theorisations in a field dominated by interpretive approaches. Lin et al. [32] observe that the link between macro socio-political context and local innovation, captured by critical approaches, sheds light on aspects of oppression and alienation that may not be caught by interpretive analyses. Critical research is characterised by coexistence of theorisation and transformation of an oppressive status quo [38], and seeks to illuminate alienating conditions with a view to tackle the root causes of statuses of social domination. Its transformational intent, as well as its focus on macro socio-political dynamics, marks its difference from positivist and interpretive research paradigms.

While established work in the information systems (IS) field depicts critical theory as hegemonised by the three Western streams led by Bourdieu, Foucault and Habermas [37], indigenous schools of thought such as subaltern studies have found limited recognition in IS so far. Originating from a South Asian scholars' collective [21], the subaltern studies school is underpinned by its focus on a devoiced and objectified entity, indeed referred to as the subaltern [43], whose condition is dictated by exclusion from the hegemonic structure of society [19]. Impinging on South Asian experiences of postcolonialism, subaltern scholars draw on Gramscian 
theory to carve a space for narratives of subalternity in postcolonialism, using the South Asian experience to construct a conceptual apparatus to narrate marginalisation of individuals and communities.

While firmly originating in and for South Asia, the focus of subaltern studies captures popular politics affecting "most of the world" [9] as a result of postcolonial practices. Drawing on Gramsci's [19] notion of hegemony as a process through which ruling classes leverage cultural institutions to maintain their power, the subaltern school of thought conceives hegemonic discourse by the dominant classes as the mainstream narrative acknowledged in society [32]. Such a dominant discourse predominates on narratives by those left at the margins of society, whose subalternity results in devoicing [43]. Subordination leaves the subaltern confined to particular ways of encountering, or "seeing", the mainstream: such encounters take place through a host of technologies of rule [42], which crystallise the position of the mainstream as dominant and that of the subaltern as recipients of mainstream narratives. Paradigmatic of technologies of rule is the Indian census, which inscribes individuals into colonially-established categories without giving them a say on the matter, and hence leaving them devoiced [13].

Devoicing and marginalising as these can be, encounters with the subaltern are far from being depicted by the mainstream as a means of subjugation. Following Gramsci's [19] theorisation of paternalism, the mainstream "assumes they have the right and obligation to assimilate (help) those at the margin, often without any consultation of the subaltern" [32]. This reflects a paternalistic ideology in which the mainstream pursues the "moral duty" of assisting the subaltern, without however engaging these as an interlocutor in dialogue and hence, perpetuating the devoicing nature of their relation [21]. In exemplifying the position of the subaltern in society, Chatterjee [9] theorises a dichotomy between what he refers to as civil and political society: while a civil society of equals is enabled to establish a dialogue with those in power ("the state" in Chatterjee's writing), a political society encompassing the poor and marginalised is detached from the state and unable to establish an equal dialogue with its representatives.

With the intent of narrating stories of devoiced individuals and communities, two recent studies in ICT4D have explicitly turned to a subaltern perspective, to study non-technical rationalities in Ghana's customs [1] and the devoicing of tribal communities in Indian social protection schemes [34]. Furthermore, Lin et al. [32] - while claiming a postcolonial, rather than specifically subaltern, perspective for their study leverage the notions of mainstream, devoicing, subalternity and paternalism to examine an ICT4D project in Taiwan, exposing a narrative of discomfort by the aboriginal recipients silenced by a mainstream story of success. Enacting critical theory's focus on alienation from the perspective of the oppressed, subaltern studies offer a lexical apparatus to analyse situations of perpetuated asymmetrical power, which provides the basis to consider such an apparatus in the study of digital workers battling crisis in COVID-19.

\section{Methodology}

To study the condition of platform workers during COVID-19, we collected 68 among company statements, survey reports, press releases and ethnographic narrations from workers released after the WHO declaration of COVID-19 as a pandemic. Our source selection followed Avgerou [5] in cautioning against the pitfalls of vulgar eclecticism and inbreeding. Vulgar eclecticism is the ad hoc selection of ideas from a body of literature, while inbreeding is the act of focusing too narrowly on a set of sources aligning with one of the parts in the debate. Based on the literature review conducted above, there were three core dimensions of representativity to ensure:

- Actor perspectives - a primary read of sources ( $\mathrm{n}=$ 15), conducted on 28 April 2020, has revealed a discrepancy of voices between statements released by the platforms and ethnographies of work during COVID-19 narrated by the workers. The latter also include third-party reports based on interviews with workers, which are primarily revealing of their issues and uncertainties during the crisis. We have hence split our source database by collecting an equal number $(\mathrm{n}=$ 30) of sources from a platform perspective and from a workers' one. Eight more sources, classed as overview reports and describing the environment without a clear positional value, have been added to form a more complete picture of the situation.

- Geography - our literature review of platform work has revealed systematic differences between global North and South, on key dimensions such as relative wages and cruciality of this type of work in generating livelihoods for workers. For this reason, we have divided our country-specific sources (46 out of 68) by location: the split is slightly in favour of countries classed as low and middle-income by the World Bank, which constitute 26 of our country-specific sources vs. 20 from high-income countries. The database covers sources from 18 countries across five continents.

- Type of platform: taxonomies by Heeks [25] and Graham and Woodcock [18] reveal the importance of 
distinguishing location-specific from online labour platforms. Both have been affected by COVID-19, but the literature convenes that location-specific workers such as ride-hailing, food delivery or domestic service operators have been hit in more measurable ways, in terms of both income loss and risk of contracting the virus while working. For this reason, most sources in our database (50 vs. 18) pertain to location-specific platform workers, whereas the remainder are split into onlydigital work (6) and encompassing both digital and physical (12).

Since COVID-19 has been declared a pandemic on 11 March 2020, this date has been established as cut-off for our source collection. Our sources have been collected between this date and 30 June 2020, with a greater concentration in the second part of the time span due to source availability growing over time along all the three dimensions delineated above.

\section{Platform Workers and COVID-19: A Subaltern Theory Analysis}

Core concepts from subaltern studies offer a lens to make sense of the condition of digital platform workers under COVID-19. Below we illustrate our use of the conceptual apparatus from a subaltern theoretical approach, which we apply to our sources database.

\subsection{Mainstream Discourse}

In examining digital platform work from the perspective of platform representatives, a common thread emerges around the position of workers. Beyond the logic of industry transformation describing the business model of platforms, a dominant discourse equates platforms, across different industries, to generators of job opportunities for unemployed and vulnerable people. This goes beyond the customercentred transformation of access to core services such as transport or food delivery, and marks a worker-centred transformation that affords new flexible, well-paid (or at least, decently paid) jobs. It is on this vision, combined with success stories of marginalised people building livelihoods with platform work [45], that the shared orthodoxy of "digital platforms for socio-economic development" has been constructed.

Such a common thread is central to understanding digital labour platforms' responses in the wake of COVID-19. Supported by media reports, platforms' web communications point to sharing the willingness of executives to help workers in crisis, taking action

${ }^{3}$ https://www.fiverr.com/pages/covid-19-resource-center-ceoletter?cms=lunar, accessed 20 October 2020 through sets of dedicated measures. Such an intent is common across digital and physical work platforms, both of which have expressed firm intentions of assistance reflected, for example, by Fiverr's CEO:

\begin{abstract}
We are here to help, and every day we are adding new resources, donating online courses, and gathering offers from other companies around the world that make the lives of businesses and freelancers better at this challenging time. We also built exclusive partnerships that help our freelance community, and we created simple guidance on how to access the US Government Cares Act Stimulus bill for SMBs and freelancers. ${ }^{3}$
\end{abstract}

This intent is translated into lists of measures taken by each platform to protect workers, lists that are usually provided in COVID-19 specific sections of platforms' websites. For example, Upwork offers a list of measures described as critical by the platform's CEO, including (1) helping self-employed individuals and entrepreneurs maintain business continuity, (2) supporting freelancers in a time of need, (3) facilitating earnings from nonUpwork clients, and (4) accelerating receipt of payments. ${ }^{4}$ Among other actions the list remarks the platform's role as Founding Partner of the Freelancers Relief Fund, established by the Freelancers' Union to assist workers induced into financial hardship by COVID-19. All these measures, sometimes detailed in open letters from executives, signal the platforms' declared intention to actively care for workers in crisis.

When it comes to location-specific platforms, the situation is made more complex by the drastic, direct impact of the crisis on workers' conditions. Locationspecific workers face, as noted above, a difficult dichotomy: some of them, such as cleaners or providers of handyman-type services, have seen their job opportunities drastically reduced or suspended by lockdown measures. Others, such as ride-hailing app drivers or food delivery couriers, found themselves on the frontline of the pandemic, with key workers roles that some countries officially recognised (as the UK government and multiple Indian states did for food delivery operators). On a general rule, these workers are left with the option to continue to work, with platforms establishing new conditions in harmony with local government regulations.

For location-specific workers too, platforms have taken it to web communication to explicate the ways they will enact their intent to protect workers. As noted by the survey from the Fairwork Foundation [14] mentioned above, the large majority of the 191 platforms surveyed have declared taking dedicated

\footnotetext{
${ }^{4} \mathrm{https}$ ://www.upwork.com/resources/letter-community-covid-19, accessed 20 October 2020
} 
measures to help workers, ranging from financial assistance to subsidising protective equipment and, in some cases, health insurance [14]. Paradigmatically, Uber UK's web page on "COVID-19: Your Questions Answered" details a list of measures in a Q\&A form, which can be invoked by currently active drivers and include the following: ${ }^{5}$

- Making drivers aware of possible eligibility for the UK Government's Self-Employment Income Support Scheme (SEISS), followed by a list of eligibility requirements,

- Making drivers aware of possible eligibility for Universal Credit, as well as the possibility to get advice (from an external party) for those who are "struggling to pay their bills" due to coronavirus,

- Offer a financial assistance policy ( $£ 100$ per week for up to 14 days) to drivers who either (a) have been diagnosed with COVID-19, (b) have been told to selfisolate by a licensed medical provider or public health authorities, or (c) have NHS 111 self-serve certification,

- Vehicle providers offering temporary reduction on weekly payments for rentals, to be reviewed on a caseby-case basis, and working with selected insurance providers to "ask that they find options" to reduce drivers' costs for vehicle insurance,

- Reimbursement (up to £25) on purchases of personal protective equipment,

- Protection of Uber Pro status for drivers that hold it, even in the absence of the regular rides that are normally needed to maintain such a status.

The list, accompanied on the web page by a video from the head of Uber UK's Driver Operations team, ends with the provision of the phone number and website of a registered charity, to be contacted "if you feel like circumstances related to coronavirus are impacting your mental health". While country-specific in its provisions and phrasing, such a list exemplifies how a leading actor in the platform economy is handling communication on protective measures for workers during the crisis.

All these measures, varying by type of platform but grouped by a common protective intent, feed into a shared narrative of platforms' declared goal to protect workers' well-being and financial survival. Clear in its protection focus, this narrative lies in continuity with assertions - made by the platforms since well before the crisis - portraying platforms as job creators for the vulnerable and marginalised. A dominant discourse, resonating across types of platform and geographical locations, invests platforms of a protective role that is strengthened and highlighted during COVID-19.

\subsection{Devoicing}

While platforms invest themselves with a publicly declared protective role, a different story - one of perpetuated gaps of power and information - is narrated across the worker-centred sources examined here. It should be noted, in the first place, that relief measures vary considerably across platforms and countries, and so do the social welfare policies that platform workers can access. But in spite of such variations, a common thread of lacking protection and information emerges across workers' reports, a thread that articulates around the concepts of abandonment, risk and disempowerment suffered during COVID-19. We review such themes based on the workers' ethnographies and third-party reports collected across different nations.

Abandonment: pervading workers' reports is, in the first place, the sense of "being left alone" [4] by platform representatives, a narrative that stands in stark contrast with the intent of protection expressed by the platforms. The theme of abandonment takes two shapes: first, lack of crucial information to the worker is reported across countries, with multiple instances [14] in which workers have learned about COVID-19 protective measures from the media rather than their employer. Reports from Brazil, India and South Africa $[4,20,23]$ also reveal information on customer protection being more detailed and accessible than information on worker protection, a gap also identified in terms of protective measures (food delivery couriers in India, for example, enact contact-free delivery, but not contact-free collection, which perpetuates risk of exposure).

Secondly, the lack of protective systems perceived as effective further contributes to a narrative of abandonment. A common thread across workers' reports concerns loss of income, estimated by the Fairwork Foundation [14] at an average of two-thirds of pre-crisis income. The informal nature of most platform work - resulting in workers living off a daily wage makes this aspect particularly difficult for workers: and yet, financial assistance policies (where present) are reported to be systematically challenging to access and, where accessible, limited in the amounts allowed. In Brazil, where reimbursement of Uber drivers for PPE is

\footnotetext{
${ }^{5}$ https://www.uber.com/en-GB/blog/covid-update/, accessed 20 October 2020
} 
limited to 20 BRL (ca. 3.5 Euro), financial assistance is based on the drivers' performance over the three months before request [20], and request for it automatically results in suspension of the drivers' account, before notification of the outcome. Such uncertainties, grouping together workers' narratives from across our database, cast a shade of doubt on the mainstream discourse of protection narrated by platforms.

Risk: a second narrative revolves around workers' perception of risks endured at the time of crisis. Some risk components are directly visible: among these are risks of a financial nature, since financial assistance even when obtained, in spite of strict requirements - is reported to be too limited to offset workers' equipment cost, as reported in South Africa [4]. Other risk components are, instead, less visible: self-ethnographies [23] and surveys [30] of food delivery couriers in India report drivers being exposed to infection having to stand in crowded queues, made more crowded by the limited opening hours of restaurants during lockdown. In addition, selected platforms in India pay workers a minimum daily wage if they complete a certain number of orders within a given number of hours, leading to drivers taking longer trips which heighten the trafficrelated risks they normally endure. Perception of risk a theme that pervaded pre-crisis reports as well - is heightened during the crisis, putting workers in front of the dilemma, resonating across countries, between giving up work - protecting health risk for workers and their families - and continuing to work, exposing themselves to the virus by daily work operations [14].

Disempowerment: a third thread of connection among workers' views, emerging in continuity with precrisis gaps in power and information, refers to the perception of disempowerment towards the effects of the crisis. Reports reveal a twofold origin of disempowerment: first, lacking recognition of workers' position as employees - noted above as a source of precarity - results in lack of exactly those forms of health insurance, sick leave and protection that pertain to formal employment, whose relevance to workers' lives spiked with COVID-19. Secondly, the abovementioned issue of information asymmetries [26] is perpetuated during the pandemic, with the issue of "whom to" speak to magnified by the observed platforms' trend to place responsibility on governments for social welfare, and on workers for respect of protection norms [25]. Viewed in this light, platforms' mainstream discourse of protection is balanced against inability of workers to access core protection systems, or indeed leverage unionisation to obtain prompt help under tight crisis conditions.
Shared across national contexts, and notwithstanding important exceptions that we review below, themes of abandonment, risk and disempowerment group together workers' narratives collected under COVID-19. In Guha and Spivak's [21] theorisation of subalternity, the act of devoicing is constitutive of the subaltern condition, confining the subaltern as a result of diversity from the hegemonic discourse that prevails. Placed against a discourse centred on protection and care for the worker, a narrative of systematic lack of protection and care emerges from the workers' discourse, creating a counternarrative that, while visible on dedicated spaces, is silenced and devoiced in the platforms' discourse.

\subsection{Paternalism}

Across the platforms reviewed, a further common point lies in the apparent assumption of "knowing what the workers need" which mirrors the traits of paternalistic discourse in subaltern theory. In their descriptions of responses to COVID-19, multiple platforms report being in constant contact with workers, and to be active listeners in devising measures to protect them. Yet, a review of the worker-centred sources in our database reveals systematic gaps between these measures and actions that would be important for workers. Three core points reveal how platforms are indeed taking response measures, but quite different from those required by workers in the current crisis situation:

- Workers' voices, as noted by the Fairwork Foundation [14], are uniform in stating that the main issue is the loss of income resulting from the pandemic. But among the platforms they surveyed, only few have adopted direct policies to increase pay for those in work. Importantly, platforms that offer financial assistance most often do so as a substitute for it, not a completion: as ethnographies reveal, it is exactly this point that leads many ridehailing drivers to refrain from requesting assistance, a request which - if denied - would deprive them of subsidy and work earnings altogether [20]. At the same time, platforms are shown to be taking action to expand their businesses, reducing client fees or expanding their services [14]: in India, some platforms have expanded to include delivery of groceries and vegetables, with the workers however reporting this has not lead to increases in orders for them [30].

- Workers' voices are similarly uniform in stating the need for sick pay or health insurance, especially workers of platforms whose activity exposes them to the risk of COVID-19 infection. Yet, while numerous platforms have offered or subsidised some protective equipment, 
the forms of health insurance that workers require are still an extremely rare occurrence. A study of South Africa [15] has revealed that only three out of 13 surveyed platforms offer some form of healthcare assistance, with multiple platforms failing to adapt the provision of health insurance in the light of the current emergency. For workers still operating, this means going to work knowing they will not be compensated in case they get sick, a risk suffered with particular anxiety by workers whose income is the only one in their household [20].

- In the critical situation arising from COVID-19, diverse forms of workers' collective action across the world have revealed the importance of representation for workers to establish communication with employers. But among platforms, whose representatives write open letters to workers as well as shareholders and clients, the Fairwork Foundation survey has found no evidence of engagement with worker associations, neither with the strikes and petitions that have emerged in several parts of the world [14]. Workers' reports reveal that the importance of representation has grown in the current circumstances: and yet, little or no response emerges from the platform side, adding to the issue of asymmetrical information that limits opportunities for building solidarity networks. In light of the importance of representativity especially during emergency, findings on its absence further problematise the position of workers, who often find themselves with subsidised PPE but without the possibility to effectively communicate their needs.

In Guha and Spivak's [21] vision of subalternity, the mainstream builds for itself the role to "care for" those at the margin, without however consulting them or treating them as equals [32]. Assisting the subaltern is constructed as a moral duty, which is however accomplished without engaging them into dialogue, as it would be with Chatterjee's "civil society" [9]. Overall, the platforms reviewed here manifest an intent to care for the workers, but deciding - by themselves what is important, without engaging any meaningful dialogue with them. Lack of representation, which was already rare across the platforms and is starkingly missing during COVID-19, exemplifies an attitude that sees the worker as recipient of protective measures, but not an as an active part to consult in their formulation.

\section{Discussion and Conclusions}

Subalternity theory offers a conceptual apparatus to narrate marginalisation of individuals and communities, making sense of devoicing practices and visualising their structural underpinnings. While it finds limited space in IS research so far, the theory presents important affordances to understand the structures of subalternity, and differentiates from Western critical theories [33] for its specific focus on such structures. Our analysis in this paper shows how subalternity theory supports understanding of the structural vulnerability of digital platform workers, reinforced from the COVID-19 crisis which resulted in greater visibility of extant power and informational asymmetries in digital work.

Our analysis illuminates the creation of mainstream discourse from platform representatives, which however translates into bland paternalism rather than meaningful dialogue with workers. In parallel, we have elicited a silenced workers' narrative which reveals dimensions of abandonment, risk and disempowerment that dominant narratives do not explore, but that resonates with recent research on the institutional voids [24, 33] perpetuated by digital labour. Concepts of mainstream discourse, devoicing and paternalism allowed us to illuminate key aspects of workers' condition, revealing blind spots [1] that the subalternity theory allows to conceptualise. The mainstream discourse is powerful and pervasive [32], but the conceptual apparatus of subalternity theory allows sighting and narration of otherwise silenced dynamics of devoicing and subordination.

Importantly, not all platforms adhere to the problematic pattern identified above. The Fairwork Foundation [14] presents a set of examples of best practices from platforms during COVID-19, such as the South African domestic work platform SweepSouth which has created a readily accessible workers' fund paid by clients and investors [15]. Other platforms have instituted forms of health assistance and informed workers of these at the beginning of the crisis. Such positive practices are however inscribed in a picture of prevailing inaction [14]: placed against the dominant protection discourse, this inaction constitutes the heart of the problem, especially if seen in relation with the established vulnerabilities that the crisis has brought to light.

This study has two main orders of implications. For the literature on digital labour, the study offers a core theory to understand vulnerabilities that, as it has been noted $[20 ; 25]$ have been made visible by COVID-19, but are ingrained in conditions that became crystallised well before the emergency. The recency of the crisis implies the need of a conceptual system to make sense of it, which the lexicon of subalternity theory provides. As future research is conducted on the medium- and long-term consequences of the crisis, the theory offers the concepts to develop analyses centred on the critical condition of workers and its underlying causes.

Secondly, our analysis yields implications for the study of emerging networks among workers subjected to the devoicing practices examined here. Recent works 
in social movement studies [6] observed that a datafied society implies new forms of organisation, which make representation possible across boundaries as shown, for example, by recent gig worker strikes in Latin America [28]. As critical research combines theorisation with transformation of extant situations, subalternity theory offers a means to build awareness of devoicing, generating important conditions for creation of such solidarity networks.

This paper makes a study of secondary sources, which offers a clear means to map a situation that is affecting labour markets on a global scale. But while solid as a mapping instrument, secondary research does not afford the possibility of voice-giving provided especially by primary research with affected workers. While the self-ethnographies of workers reviewed here have partially filled that gap, future work requires primary sources to delve into how subalternity operates and the shapes it takes under the current crisis. In a tradition of digital labour literature that places workers at the centre of analysis, future studies are to be centred on workers' direct experience of COVID-19, translating into reality the transformative intent that underpins critical research.

\section{References}

[1] Addo, A., Subalternity in Information Systems in Developing Countries: A Critical Analysis of Ghana's TRADENET, in International Conference on Social Implications of Computers in Developing Countries, Springer, Cham, 2017, pp. 573-592.

[2] Agrawal, A, Horton, J., Lacetera, N. \& Lyons, E., Digitization and the Contract Labor Market: A Research Agenda, NBER Working Paper 19525, NBER, Cambridge, MA, 2013.

[3] Anwar, M.A., \& Graham, M., "Between a Rock and a Hard Place: Freedom, Flexibility, Precarity, and Vulnerability in the Gig Economy in Africa", Competition and Change, Special Issue on Digitalisation and Labour in the Global Economy, 2020, pp. 1-22.

[4] Anwar, M., "We work for Uber:" South Africa's gig workers left alone at the wheel, African Arguments, https://africanarguments.org/2020/04/28/we-work-for-ubersouth-africa-covid-19-gig-drivers-alone-wheel/, 2020.

[5] Avgerou, C., "Discourses on innovation and development in information systems in developing countries' research", Journal of Information Technology, 23(3), 2008, pp. 133-146.

[6] Beraldo, D., \& Milan, S., "From data politics to the contentious politics of data", Big Data \& Society, 6(2), 2019, pp. 1-11.

[7] Berg, J., Furrer, M., Harmon, E., Rani, U. \& Silberman, M.S., Digital Labour Platforms and the Future of Work: Towards Decent Work in the Online World. International Labour Organization, Geneva, Switzerland, 2018.
[8] Bergvall-Kåreborn, B. \& Howcroft, D., “Amazon Mechanical Turk and the commodification of labour", New Technology, Work and Employment, 29(3), 2014, pp. 213-223. [9] Chatterjee, P., The politics of the governed: Reflections on popular politics in most of the world. New York, Columbia University Press, 2004.

[10] Chen, J.Y., \& Qiu, J. L., "Digital utility: Datafication, regulation, labor, and DiDi's platformization of urban transport in China", Chinese Journal of Communication, 12(3), 2019, pp. 274-289.

[11] Codagnone, C., Abadie, F. \& Biagi, F., The future of work in the 'Sharing Economy'. Market efficiency and equitable opportunities or unfair precarisation?, EC Joint Research Centre, Seville, 2016.

[12] D'Cruz, P. \& Noronha, E., "Positives outweighing negatives: The experiences of Indian crowdsourced workers", Work Organisation, Labour \& Globalisation, 10(1), 2016, pp. 44-63.

[13] Dirks, N. B., Castes of mind. Colonialism and the making of British India, Princeton, Princeton University Press, 2001.

[14] Fairwork Foundation, The gig economy and COVID-19: Looking ahead, https://fair.work/wpcontent/uploads/sites/97/2020/09/COVID-19-Report-

September-2020.pdf, 2020.

[15]Fairwork Foundation, Gig workers, platforms and government during COVID-19 in South Africa, https://fair.work/wp-

content/uploads/sites/97/2020/05/Covid19-SA-Report-

Final.pdf, 2020.

[16] Graham, M., Woodcock, J., Heeks, R., Mungai, P., Van Belle, J.P., du Toit, D., \& Silberman, S.M., "The Fairwork Foundation: Strategies for improving platform work in a global context", Geoforum, online 20 February, 2020.

[17] Graham, M., Hjorth, I., \& Lehdonvirta, V., "Digital labour and development: Impacts of global digital labour platforms and the gig economy on worker livelihoods", Transfer: European Review of Labour and Research, 23(2), 2020, pp. 135-162.

[18] Graham, M., \& Woodcock, J., "Towards a fairer platform economy: introducing the Fairwork Foundation", Alternate Routes, 2018, pp. 242-253.

[19] Gramsci, A., Selection from the Prison Notebooks, London: Lawrence and Wishart, 1971.

[20] Guerra, A., Managing uncertainty at your own expense: Brazilian Uber drivers during the COVID-19 pandemics, https://data-activism.net/2020/06/bigdatasur-covidmanaging-uncertainty-at-your-own-expense-brazilian-uberdrivers-during-the-covid-19-pandemics/, 2020.

[21] Guha, A. G. \& Spivak, S.G., Selected subaltern studies, Bangalore, Oxford University Press, 2018.

[22] Koskinen, K., Bonina, C., \& Eaton, B., Digital platforms in the Global South: Foundations and research agenda, In International Conference on Social Implications of Computers in Developing Countries, Springer, Cham, 2019, pp. 319-330.

[23] Krishna, S., The role of a gig worker during crisis: Consequences of COVID-19 on food delivery workers in $\begin{array}{llll}\text { south India, } & \text { IFIP } & 9.4 & \text { blog, }\end{array}$ https://ifip94.wordpress.com/2020/04/13/the-role-of-a-gigworker-during-crisis-consequences-of-covid19-on-fooddeliver-workers-in-south-india/, 2020. 
[24] Heeks, R., Eskelund, K., Gomez-Morantes, E., Malik, F., \& Nicholson, B., Digital labour platforms in the Global South: Filling or creating institutional voids? Working paper 86, Digital Development series, Centre for Digital Development, 2020.

[25] Heeks, R. Protecting gig workers during COVID-19: What platforms must do, ICTs for Development blog, https://ict4dblog.wordpress.com/2020/04/27/protecting-gigworkers-during-covid-19-what-platforms-must-do/, 2020.

[26] Heeks, R. Decent work and the digital gig economy: a developing country perspective on employment impacts and standards in online outsourcing, crowdwork, etc. Development Informatics Working Paper, (71), 2017.

[27] Howcroft, D., \& Bergvall-Kåreborn, B. "A typology of crowdwork platforms",Work, Employment and Society, 33(1), 2019, pp. 21-38.

[28] Howson, K., Ustek-Spilda, F., Grohmann, R., Salem, N., Carelli, R., Abs, D., Salvagni, J., Graham, M., Balbornoz, M.B., Chavez, H., Arriagada, A., and Bonhomme, M., "'Just because you don't see your boss, doesn't mean you don't have a boss': COVID-19 and Gig Worker Strikes across Latin America", International Union Rights Journal, 2020, pp. 2022.

[29] Kuek, S.C., Paradi-Guilford, C., Fayomi, T., Imaizumi, S., Ipeirotis, P., Pina, P. \& Singh, M., The Global Opportunity in Online Outsourcing, World Bank, Washington, DC, 2015.

[30] Lalvani, S., and Seetharaman, B., The personal and social risks that India's food delivery workers are taking during COVID-19. https://thewire.in/business/covid-19-fooddelivery-workers, 2020

[31] Lehdonvirta, V., Barnard, H., Graham, M. \& Hjorth, I. Online Labour Markets-Levelling the Playing Field for International Service Markets?, Oxford Internet Institute, Oxford, UK, 2020.

[32] Lin, C. I., \& Myers, M. D., "Extending ICT4D Studies: The Value of Critical Research", MIS Quarterly, 39(3), 2015, pp. 697-712.

[33] Malik, F., Heeks, R., Masiero, S., \& Nicholson, B., Digital platform labour in Pakistan: Institutional voids and solidarity networks. European Conference of Information Systems, Marrakesh, 15-18 June, 2020.
[34] Masiero, S., Subaltern studies: Advancing critical theory in ICT4D, European Conference of Information Systems, Portsmouth (UK), 23-28 June, 2020.

[35] Masiero, S., \& Nicholson, B., Competing logics: Towards a theory of digital platforms for socio-economic development, IFIP 9.4 European Conference, Salford, 10-12 June, 2020.

[36] Mpofu, T., Tsibolane, P., Van Belle, J.P., and Heeks, R. Risks and Risk-Mitigation Strategies of Gig Economy Workers in the Global South: Ride-Hailing in Cape Town, IFIP 9.4 European Conference, Salford, 10-12 June, 2020.

[37] Myers, M. D. and H. K. Klein, "A set of principles for conducting critical research in information systems", MIS Quarterly, 35(1), 2011, pp. 17-36.

[38] Myers, M. D. "Qualitative research in information systems", MIS Quarterly, 21(2), 1997, pp. 241-242.

[39] Nicholson, B., Nielsen, P., Sæbø, J., \& Sahay, S., Exploring tensions of global public good platforms for development: the case of DHIS2, in International Conference on Social Implications of Computers in Developing Countries, Springer, Cham, 2019, pp. 207-217.

[40] Pacis, J., A catch-22 for on-demand cleaners in the Philippines. Bot Populi, https://botpopuli.net/a-catch-22-foron-demand-cleaners-in-the-philippines, 2020.

[41] Rockefeller Foundation, Online Work: A New Frontier for Digital Jobs Africa. https://www.rockefellerfoundation.org/blog/online-worknew-frontier-digital-jobs/, 2014.

[42] Rose, N., Powers of freedom: Reframing political thought, London, Cambridge University Press, 1999.

[43] Spivak, G. C., Subaltern studies: Deconstructing historiography, in Guha, R. and G. C. Spivak (eds), Selected subaltern studies, Oxford: Oxford University Press, 1988, pp. 3-34.

[44] Wood, A. J., Graham, M., Lehdonvirta, V., \& Hjorth, I. "Good gig, bad gig: Autonomy and algorithmic control in the global gig economy", Work, Employment and Society, 33(1), 2019, pp. 56-75.

[45]World Bank, Growing innovation, fostering entrepreneurship: infoDev Annual Report. Washington DC: World Bank, 2013.

[46] Zainab, K. Beauty and the Platform Economy, Bot Populi, https://botpopuli.net/beauty-platform-economyurban-company-women-gig-workers, 2020. 